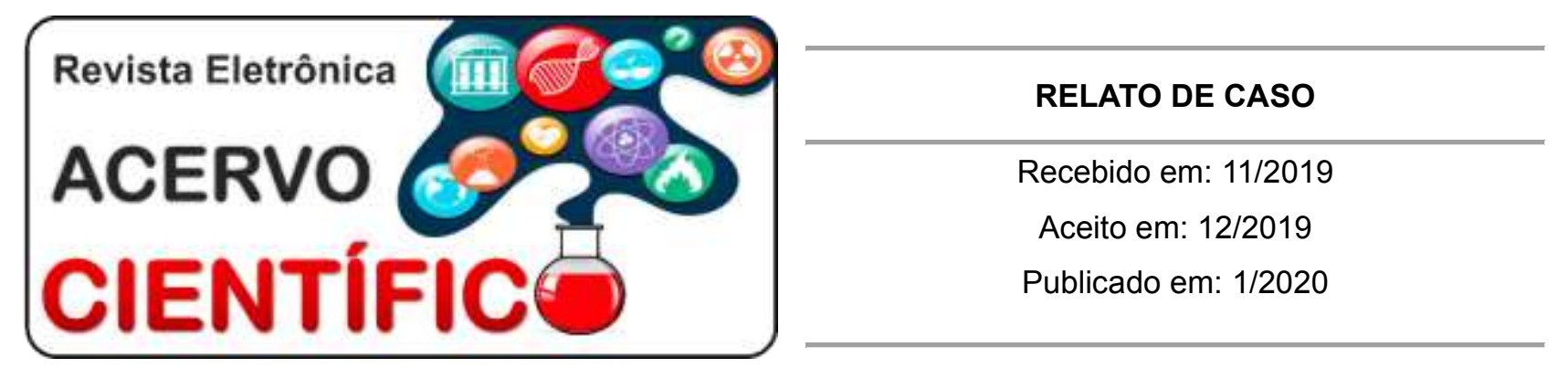

\title{
Celulite juvenil canina em Dachshund: relato de caso
}

\author{
Juvenile Cellulitis Canine in Dachshund: Case Report
}

\author{
Celulitis Canina Joven en Perro Dachshund: Informe de Caso
}

Jaqueline Lustosa Rodrigues Camapum¹, Gardênia Alves da Silva1', Cristian Francisco de Carvalho Pereira $^{1}$, Fabiane Leite da Silva ${ }^{1}$, Nathália Castelo Branco Barros ${ }^{1 *}$, Ana Paula Barros Fonseca ${ }^{1}$, Nayara Kelen Miranda dos Santos ${ }^{1}$, Vitória de Cássia Coelho Rodrigues ${ }^{1}$, João Gabriel Melo Rodrigues ${ }^{1}$, Kátia Regina Ferreira Sousa¹.

Resumo: Esse artigo relata um caso de Celulite Juvenil Canina (CJC) em um filhote da raça Dachshund na cidade de Teresina - PI, com tratamento responsivo, descrevendo sinais clínicos, abordagem clínica, terapia instituída e resposta do animal ao tratamento. Este apresentava histórico de otite crônica bilateral, com estenose em conduto esquerdo, secreção purulenta e crostas em todo o pavilhão auricular, dor, além de apatia, falta de apetite, vocalização e linfonodos submandibulares aumentados, sendo tratado para otite e, passados quatro dias, manifestou alopecia, despigmentação de lábios, focinho e região periocular, além de edema, crostas e pústulas nessa região, sugerindo CJC. Após diagnóstico clínico associado aos exames complementares, iniciou-se o tratamento imunossupressor e antibiótico, onde o animal apresentou remissão dos sintomas em 40 dias. O trabalho evidencia a ocorrência de CJC em filhote, bem como a importância do diagnóstico dessa doença para o devido tratamento e obtenção de cura do paciente.

Palavras-chave: Celulite, Filhote, Dachshund.

\begin{abstract}
Abstract: This article reports a case of canine juvenile cellulitis (CJC) in a Dachshund breed puppy in the city of Teresina - PI, with responsive treatment, describing clinical signs, clinical approach, established therapy and the animal's response to treatment. He had presented a history of bilateral chronic otitis, with left conduit stenosis, purulent secretion and crusts throughout the auricular pavilion, pain, in addition to apathy, lack of appetite, vocalization and increase of submandibular lymph nodes, being treated for otitis and, after four days, he manifested alopecia and depigmentation of lips, muzzle and periocular, as well as edema, crusts and pustules in this region, suggesting CJC. After clinical diagnosis associated with complementary exams, the immunosuppressive and antibiotic treatment was started, where the animal presented symptom remission in 40 days. The study evidences the occurrence of CJC in a teresina dog, as well as the importance of the diagnosis of this disease for proper treatment and obtaining cure of the patient.
\end{abstract}

Keywords: Cellulitis, Puppy, Dachshund.

${ }^{1}$ Universidade Federal do Piauí (UFPI), Teresina-PI. *E-mail: nathalia_castelo_branco@hotmail.com 
Resumen: Este artículo informa un caso de celulitis juvenil canina (CJC) en un cachorro Dachshund en la ciudad de Teresina - PI, con tratamiento receptivo, que describe signos clínicos, enfoque clínico, terapia instituida y respuesta animal al tratamiento. Tenía antecedentes de otitis crónica bilateral, con estenosis del conducto izquierdo, secreción purulenta y formación de costras en todo el oído, dolor, apatía, falta de apetito, vocalización y ganglios linfáticos submandibulares agrandados, tratamiento para otitis y, después de cuatro días, alopecia manifestada, despigmentación de los labios, hocico y periocular, así como edema, costras y pústulas en esta región, lo que sugiere CJC. Después del diagnóstico clínico asociado con los exámenes complementarios, se inició el tratamiento inmunosupresor y antibiótico, donde el animal presentó remisión de los síntomas dentro de los 40 días. El estudio muestra la aparición de CJC en cachorros, así como la importancia de diagnosticar esta enfermedad para el tratamiento adecuado y la cura del paciente.

Palabras clave: Celulitis, Perro, Dachshund.

\section{INTRODUÇÃO}

Na conjuntura do mundo pet, os tutores estão cada vez mais preocupados com a saúde e bem-estar dos seus animais de estimação, resultando numa maior busca por serviços veterinários e diagnósticos completos, aperfeiçoando tratamentos e beneficiando assim a saúde animal (ECHER G, 2015).

Dessa maneira, vem sendo possível melhor diagnosticar algumas doenças e relacionar sua maior ocorrência à algumas famílias e raças específicas, como ocorre com a Celulite Juvenil Canina (CJC), também chamada de Linfadenite Granulomatosa Estéril Juvenil, doença rara que acomete cães das raças Dachshund, Golden Retriever, Labrador Retriever, Gordon Setter, Beagle e Pointer. Esse acometimento frequente e específico sugere a hipótese de haver envolvimento de fatores genéticos (GROSS T, et al, 2010).

Nas fases iniciais da doença é possível observar edema de face, principalmente lábios, focinho e pálpebras, com evolução para pápulas e pústulas de forma rápida, sendo que o pavilhão auricular também pode apresentar exsudação e edema. Outra alteração comum é a linfadenomegalia regional ou difusa, acometendo principalmente filhotes com idade entre três semanas a seis meses, sem predisposição sexual, havendo também relato de casos em adultos. Em casos graves, o animal pode apresentar anorexia, prostração e hipertermia (MILLER W, et al, 2013).

São várias as hipóteses causais da CJC, e embora a patogênese da mesma seja desconhecida, pressupõe-se que pode ser provocada por infecções virais (como cinomose, parainfluenza e adenovírus tipo 2, reações alérgicas (a vacinas, fármacos, alimentos), desnutrição, verminoses, falta de asseio e estresse. Acredita-se que a CJC seja um transtorno imunomediado, uma vez que tem natureza estéril granulomatosa e tem boa resposta a medicamentos em doses imunossupressoras, como glicocorticoides. Essas ocorrências, apesar de descritas em algumas literaturas, não possuem comprovação científica, o que reafirma a importância dos relatos de caso na elucidação de mais informações práticas sobre essa doença (SCOTT DW e MILLER WH, 2007).

O diagnóstico de CJC é desafiador e determinante, pois mesmo havendo o indicativo da idade do cão, os sintomas assemelham-se aos de pioderma e celulite de origem bacteriana, sendo necessária a realização de diagnóstico diferencial por possuírem tratamentos específicos diferentes. $O$ diagnóstico efetivo deve ser baseado no histórico do animal, sinais clínicos e exames laboratoriais como citologia e microscopia de pele, biopsia e hemograma. Trata-se de uma doença não infecciosa, em que há dermatite e linfadenite granulomatosa estéril. Os exames microscópicos e as citologias não revelam microrganismos, porém pode haver infecção bacteriana secundária (MILLER W, et al, 2013).

Quanto ao tratamento, a literatura dispõe de algumas alternativas já experimentadas, como o uso tópico de acetato de alumínio ou sulfato de magnésio que se têm bons resultados, entretanto, por serem muito dolorosos, são pouco utilizados (SCOTT DW e MILLER WH, 2007). A terapia de escolha é a administração de glicocorticoides em dose imunossupressora, até que ocorra a melhora da doença, todavia, não há 
especificação quanto ao tempo de tratamento, sendo baseado na melhora clínica do paciente. E em caso de infecção bacteriana secundária, deve-se administrar também antibióticos associados a exemplo da cefalexina, cefadroxil e amoxicilina com clavulanato de potássio (MILLER W, et al, 2013; LOPES DCS, et al., 2016)

O objetivo desse trabalho é relatar um caso de Celulite Juvenil Canina em Dachshund na cidade de Teresina - Pl, com tratamento responsivo.

\section{DETALHAMENTO DO CASO}

Um cão, macho, raça Dachshund, 30 dias de idade, pesando $1,585 \mathrm{~kg}$, foi atendido com quadro de otite crônica bilateral, apresentando estenose do conduto esquerdo, secreção purulenta e crostas em pavilhão auricular bilateral. Apresentava também apatia, dor, falta de apetite, vocalização e linfonodos submandibulares aumentados, sem alterações nas demais regiões do corpo. Foi realizada videoscopia no conduto direito, no qual estava menos inflamado, pois o animal sentia muita dor a manipulação. $O$ tratamento inicial instituído visava analgesia e redução da inflamação, por meio do uso de Predinisolona com dose de $0,5 \mathrm{mg} / \mathrm{kg}$ (dose antiinflamatória) via oral e BID (duas vezes ao dia), durante 5 dias. Além disso, foi administrado dipirona em dose de $25 \mathrm{mg} / \mathrm{kg}$ pela via oral e TID (três vez ao dia) durante 2 dias. Também foi administrado Epiotic spherulites ${ }^{\circledR}$ de uso otológico, sendo 2 gotas e BID, por 10 dias. Ainda foi administrado Natalene ${ }^{\circledR}$ de uso otológico, sendo 2 gotas e BID, durante 10 dias.

No retorno, quatro dias após a consulta ( $2^{\mathrm{a}}$ avaliação), a tutora relatou melhora da otite e dos demais sintomas, todavia, houve evolução do quadro clínico, com alopecia e despigmentação de lábios, focinho e região periocular, além de edema, crostas e pústulas nesses locais (Figura 1), sem apresentar prurido.

Figura 1 - Alopecia e despigmentação de lábios, focinho e região periocular, além de edema, crostas e pústulas observadas na segunda avaliação.

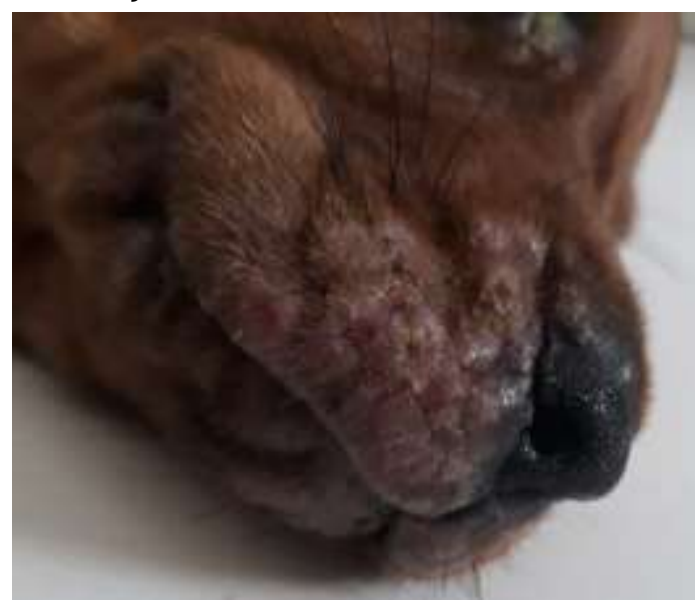

Fonte: Camapum JLR, et al., 2019.

Foram realizados os exames complementares, hemograma e sorologia IgM (Imunoglobulina M) para cinomose, o qual resultou em fraco positivo. De acordo com os resultados dos exames e com a clínica apresentada, prescreveu-se protocolo para tratamento de CJC, com aumento da dose de prednisolona para $2 \mathrm{mg} / \mathrm{kg}$ (dose imunossupressora), a qual foi administrada durante 10 dias, e em seguida reduziu-se a dose para $1 \mathrm{mg} / \mathrm{kg}$ durante 20 dias, sendo posteriormente realizado o desmame fazendo decaimento da dose por 5 dias até a finalização da mesma, conforme reavaliações periódicas. Além disso, foi instituído antibioticoterapia com ampicilina, via oral, $20 \mathrm{mg} / \mathrm{kg}$, BID, 10 dias, e diante reavaliação, alterado para TID, por mais 10 dias. Prescrito também xarope para cinomose (medicação manipulada contendo Ribavirina 30mg/0,2ml, Vitamina A $10.000 \mathrm{Ul} / 0,2 \mathrm{ml}$, Vitamina E 10mg/0,2ml, DMSO (Dimetilsufóxido) $20 \mathrm{mg} /$ 0,2 ml, Famotidina $1 \mathrm{mg} / 0,2 \mathrm{ml}$ ), $1 \mathrm{ml}$ para cada $5 \mathrm{~kg}$ de peso, SID (uma vez ao dia). 
Nove dias depois, em sua $3^{\text {a }}$ avaliação (Figura 2 - A e B), foram realizadas microscopia e citologia de pele, sendo positiva para bactérias e fungos, então foi prescrito: Itraconazol $5 \mathrm{mg} / \mathrm{kg}, 20 \mathrm{dia}$, BID e 0 shampoo Sebolytic Spherulites $\AA$ para todo o corpo, banhando semanalmente, durante um mês. Já para a região da face, o shampoo foi usado em dias alternados, durante 10 dias, com aplicações por meio de algodão úmido, e enxague do mesmo.

Figura 2 - Evolução do tratamento de CJC em Dachshund. A) e B) sinais clínicos durante tratamento para CJC, pústulas rompidas, formando as crostas e apresentando inflamação.

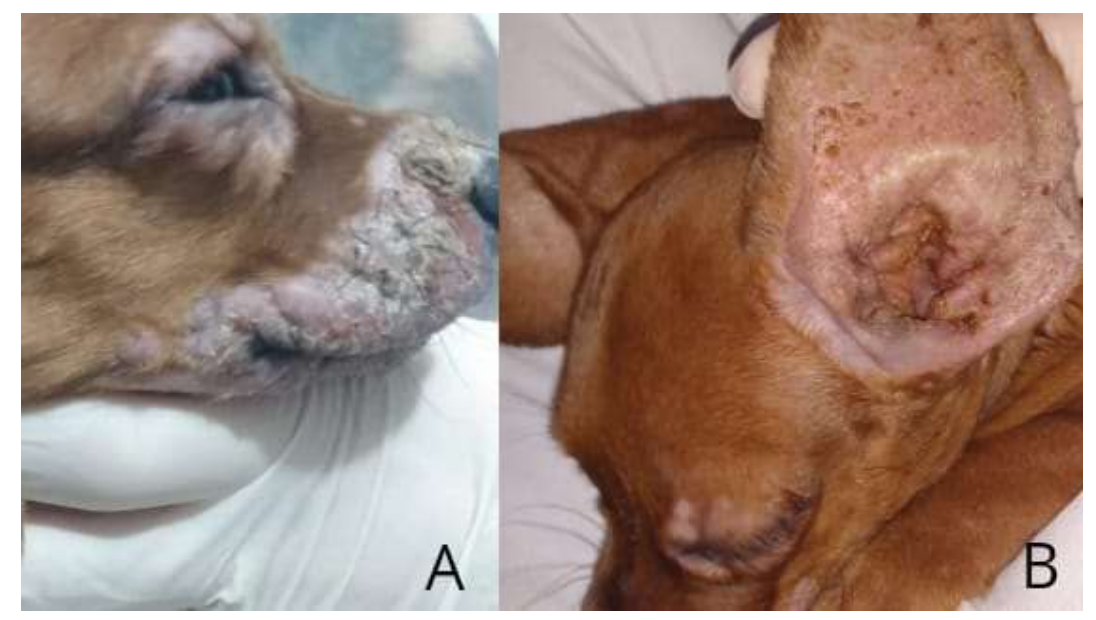

Fonte: Camapum JLR, et al., 2019.

Após nove dias, em sua 4 a avaliação, o animal retornou estando bastante ativo, porém, ao ser examinado por videoscopia foi constatado apresentação de secreção purulenta fétida, e pontos de inflamação nos condutos auditivos, além de crostas na face interna do pavilhão. A tutora relatou ter parado de administrar a medicação otológica. $\mathrm{E}$ visto que o antibiótico que estava sendo usado não apresentou resultados significativos o fármaco foi alterado, sendo prescrita a Cefalexina, $20 \mathrm{mg} / \mathrm{kg}$, via oral, BID, por 20 dias.

Em sua última reavaliação (Figura 3), foi prescrito o medicamento Pelo e Derme ${ }^{\circledR} 750 \mathrm{mg}$ com intuito de estimular a repilação da área da cicatriz, administrando 1/4 (um quarto) de comprimido por via oral, SID, por 60 dias.

Figura 3 - Animal após tratamento e remissão dos sintomas de CJC.

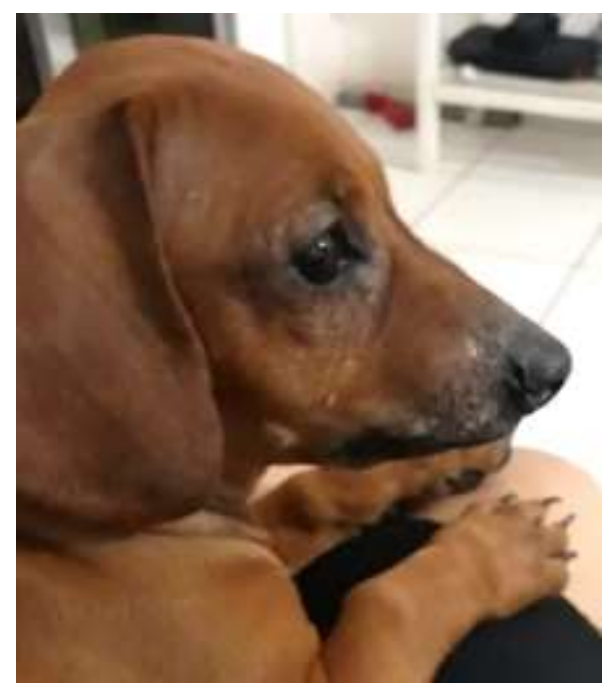

Fonte: Camapum JLR, et al., 2019. 
Após realização do exame clínico, bem como dos exames complementares, foi possível definir o diagnóstico correto da doença do animal, sendo CJC. A Terapia instituída com protocolo imunossupressor e antibiótico resultou em boa evolução, havendo melhoras nas pústulas, crostas e inflamação, obtendo êxito na remissão dos sintomas dentro de 40 dias. O prognóstico apresentou-se favorável com a evolução e cessação dos sintomas do animal deste caso aqui descrito.

\section{DISCUSSÃo}

A idade dos animais acometidos é variável, sendo marcante na fase ainda filhote, para Nagle T (2006), é mais comum em cães com menos de doze semanas de idade; já Gortel K (2013) indicou que cães de três semanas a quatro meses de idade podem ser acometidos pela CJC. Scott e Miller (2007) relataram que pode atingir cães com idade variando de cinco semanas a quatro meses, contendo ainda um intervalo de três semanas até nove meses. Hnilica KA (2011) e Miller W, et al (2013) apontaram maior incidência em filhotes de três semanas a seis meses de idade, Dhein JO, et al (2018) relatou casos entre 40 dias e três meses. O filhote relatado apresentou aos 30 dias de vida, corroborando com a literatura. Porém, de acordo com Bezerra JAB , et al (2017) ressalta-se que cães adultos também podem manifestar a doença.

Segundo Miller W, et al (2013) as lesões têm progressão rápida, onde podem desenvolver dermatite pustular e exsudativa marcante, progredindo comumente para fístulas, com drenagem purulenta e/ou hemorrágica, em um intervalo de 24 a 48 horas. O rompimento das pústulas e vesículas faz formar crostas, propiciando infecções secundárias. O caso observado teve evolução rápida, com aparecimento de alopecia e despigmentação de lábios, focinho e região periocular, além de edema, crostas e pústulas nesses locais em menos de quatro dias. Além disso, a ausência de prurido corrobora com a informação de Scott e Miller (2007), os quais ressaltam que as lesões de pele podem ser dolorosas, mas não pruriginosas.

Segundo Miller W, et al (2013) apesar de outros linfonodos poderem ser afetados, a linfadenopatia mandibular geralmente está presente, como no caso aqui descrito. Podem se desenvolver lesões nas extremidades dos membros, no abdômen, no tórax, no prepúcio e vulva, além da região perianal, que não estão presentes no referido animal.

No hemograma o animal apresentou normocitose e hipocromia, leucocitose com neutrofilia, monocitose absoluta e ainda eosinopenia absoluta. De Souza FB et al (2013), encontrou anemia arregenerativa, que é um fator comumente encontrado em animais com CJC, assim como leucocitose por neutrofilia, também identificada no caso aqui descrito, monocitose, eosinofilia e presença de bastonetes.

Na microscopia de pele realizada não foi observada presença de sarna, apresentando resultado análogo ao relato de caso sobre Celulite Juvenil Canina dos autores De Souza FB et al (2013). De semelhante modo, no relato de caso de CJC dos autores Dhein JO, et al (2018) também não foram encontrados resultados que evidenciassem a presença de sarna. Na citologia foram observadas células de descamação, estruturas basofílicas compatíveis com cocos bacterianos (>50/campo), esporos fúngicos (>50/campo) e Malassezia pachydermatis ( 1 a 16/campo). Além de células inflamatórias como neutrófilos ( 6 a $>50 /$ campo), linfócitos ( 0 a 2/campo) e macrófagos ( 0 a 3/campo), nos relatos da Dhein JO, et al (2018) todos os animais tinham infecções secundárias a CJC, sendo dois com bactérias e um com malassezia. Neste relato o animal tinha dupla infecção e com tratamentos semelhantes, houve remissão em ambos os casos.

Na primeira consulta, ao exame de videoscopia do conduto direito, foi visualizada inflamação, estenose, secreção purulenta e crostas em todo o pavilhão auricular. Tentou-se realizar o exame no conduto esquerdo, mas o animal sentia muita dor. No segundo retorno a tutora relatou ter dificuldades em administrar a medicação otológica, tendo parado com o tratamento, então na persistência do quadro a videoscopia foi repetida constatando-se presença de secreção purulenta e fétida com pontos de inflamação em ambos os condutos. Após o início do tratamento para CJC houve regressão concomitante da otite.

A sorologia IgM para cinomose foi realizada para fins de diagnóstico diferencial, tendo resultado fraco positivo, com escore 1:40. Então foi prescrito medicamento para cinomose concomitantemente aos da CJC, 
uma vez que animal não havia sido vacinado, e realizado desmame aos 20 dias de vida, considerou-se uma possível infecção viral. O caso de CJC em um animal positivo para cinomose, mesmo que em baixo score, alimenta a hipótese de que a infecção por cinomose pode ter relação na ocorrência de CJC concomitante, como já levantado por Scott DW e Miller WH (2007) sendo este ponto importante a ser observado nos demais relatos.

Com auxílio dos exames complementares o animal foi corretamente diagnosticado de acordo com Bezerra JAB, et al., (2017) e Albuquerque APS, et al., (2018) e tratado com protocolo de imunossupressão e combate a infecções secundárias, e através de constantes reavaliações obteve-se sucesso em aproximadamente 40 dias de terapia, demonstrando prognóstico favorável Lopes DCS, et al (2016); Albuquerque APS, et al (2018). Dhein JO, et al (2018) descreveram, o tratamento de três animais com CJC, utilizando imunossupressores com remissão completa das lesões em 45, 32 e 30 dias respectivamente.

No caso descrito não se sabe da existência de histórico familiar da doença, fator importante já que se trata provavelmente de uma doença autoimune de cunho genético, sendo até mesmo recomendada a retirada do animal da linha de reprodução.

Pode-se inclusive levantar a discussão de instituir o teste de cinomose em casos de suspeita de CJC, para, com os resultados obtidos, orientar um estudo específico no intuito de avaliar a existência de uma concreta relação entre essas enfermidades. Essas são apenas algumas das hipóteses causais da CJC, portanto é imprescindível a descrição de relatos sobre essa doença rara e estudos mais aprofundados sobre a etiopatogenia da mesma, verificando também o paralelismo com a cinomose.

\section{CONSIDERAÇÕES FINAIS}

Há ocorrência de Celulite Juvenil Canina associada à raça Dashchund na cidade de Teresina - PI, o tratamento imunossupressor foi efetivo no caso descrito, e há a possibilidade da relação autêntica da ocorrência de cinomose paralela à CJC. Além da constante reavaliação do quadro clínico e resposta ao tratamento.

\section{AGRADECIMENTOS}

Agradecemos à Criar Centro Veterinário por ceder o caso.

\section{SIGLAS E ABREVIAÇÕES}

BID: Duas vezes ao dia

CJC: Celulite Juvenil Canina

DMSO: Dimetilsufóxido

IgM: Imunoglobulina M

Kg: Quilograma

$\mathrm{Mg} / \mathrm{Kg}$ : Miligrama por quilograma

SID: Uma vez ao dia

TID: Três vezes ao dia 


\section{REFERÊNCIAS}

1. ALBUQUERQUE APS, et al. Celulite juvenil canina. Ciência Veterinária UniFil, [S.I.], v. 1, n. 2, maio 2018. ISSN 25957791.

2. BEZERRA JAB, et al. Canine juvenile cellulitis: a retrospective study (2009-2016). Braz. J. Vet. Res. Anim. Sci., São Paulo, v. 54, n. 4, 2017, p. 407-411.

3. DE SOUZA FB, et al. Celulite juvenil canina - relato de caso. Rev. Educ. Cont. Med. Vet. Zootec. 11(3):94-5.

4. DHEIN JO, et al. Celulite Juvenil Canina: Casos Atendidos no Dermatovet UFRGS de 2013 a 2018. COMDEV, 2018. 13: 13-15.

5. ECHER G. Relatório de estágio curricular supervisionado em medicina veterinária. Universidade regional do noroeste do estado do rio grande do Sul, departamento de estudos agrários curso de medicina veterinária. ljuí, RS, 2015.

6. GORTEL K. Recognizing pyoderma more difficult it may seem. Veterinary Clinics of North America: Small Animal Practice, Philadelphia, v. 43, n. 1, Jan. 2013, p. 1-18.

7. HNILICA KA. Small animal dermatology: a color atlas and therapeutic guide. 3. ed. St. Loius: Elsevier, 2011. 611 p.

8. LOPES DCS, et al. Celulite Juvenil Canina- Relato de Caso. Revista Brasileira de Higiene e Sanidade Animal (v.10, n.3) jul - set (2016), p. $462-469$.

9. MILLER W, et al. Small animal dermatology. 7th ed. St. Louis: Elsevier; 2013.

10. NAGLE T. Topics on pediatric dermatology. Veterinary Clinics of North America: Small Animal Practice, Philadelphia, v. 36, n. 3, May 2006, p. 557-572.

11. SCOTT DW, MILLER WH. Juvenile cellulitis in dogs: a retrospective study of 18 cases (1976-2005). The Japanese Journal of Veterinary Dermatology, Toquio, v. 13, n. 2, 2007, p. 71-79. 